Sharif University of Technology
Scientia Iranica

\title{
Expansion planning of automated sub-transmission and distribution networks integrated by distributed generations
}

\author{
M. Zohour-Attar ${ }^{a}$, J. Aghaei ${ }^{\mathrm{a}, \mathrm{b}, *}$, T. Niknam ${ }^{\mathrm{a}}$, and A. Nikoobakht ${ }^{\mathrm{c}}$ \\ a. Department of Electrical and Electronic Engineering, Shiraz University of Technology, Shiraz, Iran. \\ b. School of Energy Systems, Lappeenranta-Lahti University of Technology (LUT), Lappeenranta, Finland. \\ c. Higher Education Center of Eghlid, Eghlid, Iran.
}

Received 24 October 2017; received in revised form 23 September 2019; accepted 10 November 2019

\section{KEYWORDS}

Sub-transmission and distribution network expansion planning; Distributed generation; Distribution automation; Reliability indexes; Mixed integer linear programming.

\begin{abstract}
This paper presents Sub-transmission and Distribution Network Expansion Planning (S\&DNEP) including Distributed Generation (DG) and Distribution Automation (DA) considering reliability indices. The objective function is to minimize investment, operation, maintenance, and reliability costs subjected to AC power flow, system operation and generation unit and DG limits, reliability, and distribution automation constraints (including the constraints of protection devices and volt/VAr control mechanism). The proposed model is a Mixed Integer Non-Linear Programming (MINLP) model, which is hard to solve. For this reason, an MINLP problem is transformed into a Mixed Integer Linear Programming (MILP) model. The validity of the proposed method is investigated in the two synthetic test networks.
\end{abstract}

(C) 2022 Sharif University of Technology. All rights reserved.

\section{Introduction}

In recent years, the distribution network demand has been increasing due to population growth and the advent of new technologies. In this context, the distribution network cannot meet the increasing load placed on the system, resulting in voltage drop and power loss as well as overloading of distribution lines, as well $[1,2]$. This phenomenon reduces the reliability and power quality of the distribution network [3,4]. Therefore, Distribution Network Expansion Planning (DNEP) is required to consider the load increment and enhancement of system power quality and reli-

\footnotetext{
*. Corresponding author. Fax: +98-713-7353502
} E-mail address: aghaei@sutech.ac.ir (J. Aghaei)

doi: $10.24200 /$ sci. 2019.5435 .1270 ability $[5,6]$. The DNEP challenges are to install a new post, a distribution line, Distributed Generations (DGs), and other alternative elements for distribution networks. Accordingly, in DNEP, all the related costs should be minimized while enhancing the power quality and reliability of the system.

Different research studies have explored the problem of DNEP. Naderi and Seifi [7] presented the optimal power flow model of dynamic DNEP in the presence of DGs with the objective of minimizing investment, operation burden, and maintenance costs and employed Genetic Algorithm (GA) to solve the model. According to Zou and Prakash [8], the DNEP with DGs was modeled as a stochastic programming solved by Particle Swarm Optimization (PSO) algorithm. The uncertainty associated with loads and DGs was included in DNEP, considering reliability index and system operation limits [9]. The DNEP was formulated 
Table 1. Taxonomy of recent works.

\begin{tabular}{|c|c|c|c|c|c|c|c|c|}
\hline \multirow[b]{2}{*}{ Ref. } & \multicolumn{2}{|c|}{ Expansion planning of } & \multicolumn{2}{|c|}{ Problem based on } & \multicolumn{3}{|c|}{ Considering } & \multirow{2}{*}{$\begin{array}{l}\text { Solving } \\
\text { method }\end{array}$} \\
\hline & $\begin{array}{c}\text { Sub-transmission } \\
\text { network }\end{array}$ & $\begin{array}{c}\text { Distribution } \\
\text { network }\end{array}$ & $\begin{array}{l}\text { Power } \\
\text { flow }\end{array}$ & $\begin{array}{l}\text { Current } \\
\text { flow }\end{array}$ & $\operatorname{Re}$ & DG & DA & \\
\hline$[7]$ & & $\checkmark$ & $\checkmark$ & & & $\checkmark$ & & GA \\
\hline$[8]$ & & $\checkmark$ & $\checkmark$ & & & $\checkmark$ & & $\mathrm{PSO}$ \\
\hline$[9]$ & & $\checkmark$ & $\checkmark$ & & $\checkmark$ & $\checkmark$ & & $\mathrm{PSO}$ \\
\hline$[10]$ & & $\checkmark$ & $\checkmark$ & & & $\checkmark$ & & $\mathrm{PSO}$ \\
\hline$[11]$ & & $\checkmark$ & $\checkmark$ & & $\checkmark$ & $\checkmark$ & $\checkmark$ & GA \\
\hline$[12]$ & & $\checkmark$ & & $\checkmark$ & & $\checkmark$ & & MT-based MILP \\
\hline$[13]$ & & $\checkmark$ & $\checkmark$ & & & $\checkmark$ & & MT-based MINLP \\
\hline$[14]$ & & $\checkmark$ & & $\checkmark$ & & & & MT-based MILP \\
\hline$[15]$ & $\checkmark$ & & $\checkmark$ & & $\checkmark$ & & & MT-based MILP \\
\hline$[16]$ & & $\checkmark$ & $\checkmark$ & & & $\checkmark$ & & TLBO \\
\hline$[17]$ & & $\checkmark$ & $\checkmark$ & & & $\checkmark$ & & GA \\
\hline$[18]$ & & $\checkmark$ & $\checkmark$ & & $\checkmark$ & & & MT-based MILP \\
\hline [19] & & $\checkmark$ & $\checkmark$ & & $\checkmark$ & $\checkmark$ & & MT-based MILP \\
\hline $\begin{array}{c}\text { Proposed } \\
\text { method }\end{array}$ & $\checkmark$ & $\checkmark$ & $\checkmark$ & & $\checkmark$ & $\checkmark$ & $\checkmark$ & MT-based MILP \\
\hline
\end{tabular}

Note: Re: Reliability; DG: Distributed Generation; DA: Distribution Automation; GA: Genetic Algorithm;

PSO: Particle Swarm Optimization algorithm; MT: Mathematic Technical;

TLBO: Teaching Learning-Based Optimization algorithm: MILP: Mixed Integer Linear Programming;

MINLP: Mixed Integer Non-Linear Programming.

as a multi-stage framework from the perspectives of energy generation company in the form of the MINLP problem, solved by PSO algorithm [10].

Heidari et al. [11] presented a multi-stage DNEP with distribution automation devices; in this context, distribution automation devices facilitate the improvement of smart grid structures. Moreover, this study estimated the values of reliability indexes such as SAIDI and SAIFI and finally, employed genetic algorithm to solve the problem, i.e., MINLP problem. As demonstrated by Munoz-Delgado et al. [12], the optimal placement of DGs was considered in the case of DENP problem for minimizing the energy loss, increasing investment, and reducing operation costs, in which the non-linear equation of energy loss cost was converted into a linear equation using conventional piecewise linearization. AlKaabi et al. [13] presented the active distribution network planning considering multi-DG configurations. Also, short-term expansion planning of radial electrical distribution systems was adopted by Gonecalves et al. [14] and its base model was given as a Mixed-Integer Liner Programming (MILP) problem. Moreover, the sub-transmission expansion planning was offered by Karimi and Haghifam in [15].
In [15], the reliability, environmental and higher power quality were considered in multi-objective problems. Moreover, the active distribution network expansion planning considering storage systems was expressed by Shen et al. and Xing et al. [16,17]. Moreover, the reliability index was considered by Muñoz-Delgado et al. and Shivaie et al. in $[18,19]$ for solving the problem of distribution network expansion planning. Finally, Table 1 shows taxonomy of the proposed methodologies for the problem of sub-transmission and distribution network expansion planning.

From Table 1, the main research gaps are given as follows:

- Many researches have not considered the impacts of DNEP on the viability of sub-transmission networks. It is possible that the variation of distribution network structure gives rise to changes to the subtransmission network [20];

- Studies have not considered equations of reliability indexes in the proposed problem. In other words, they solve the proposed problem firstly and investigate the reliability index;

- Researchers use evolutionary algorithms for solv- 
ing the proposed problem. However, it is noted that these methods are based on rule of random phenomena. Since these methods function based on the iteration method, the calculation time of these methods is generally long. In addition, the evolutionary algorithms perform based on stochastic search and the global optimality of the solutions cannot be guaranteed.

To cope with the above issues, this paper presents the sub-transmission and distribution network expansion planning that considers DGs and Distribution Automation (DA) from the viewpoint of distribution companies. It is noted that the DA includes protection and volt/VAr control devices such as switches and a capacitor bank as well as other power elements. Hence, the distribution network is an active network. Moreover, the reliability indices such as CID, CIF, SAIDI, and SAIFI are considered as the constraints in the proposed problem model. The objective function is to minimize investment, operation, maintenance, and reliability costs. Also, the $\mathrm{AC}$ power flow equations, reliability constraints, system operation and generation unit limits, DG equations, DA constraints, and radial structure equations for distribution networks are the constraints associated with the base problem. This problem is the MINLP that requires long calculation time and a locally optimal solution. Hence, this paper uses an equivalent MILP model. Of note, the reactive power term is not removed in the MILP model. The main contributions of this study are summarized as follows:

- Sub-transmission and distribution network expansion planning simultaneously;

- Considering reliability indices as problem constraints;

- Considering optimal placement of DGs and DA devices;

- Presenting an MILP model;

- Contribution related to DA inclusion in DNEP.

The rest of the paper is organized as follows. Section 2 describes the problem model. Section 3 gives numerical simulations. Section 4 presents the conclusions.

\section{Problem model}

In this section, the proposed problem model is presented. In this optimization problem, the investment, operation, and reliability costs are minimized. Also, the constraints of the proposed problem are $\mathrm{AC}$ power flow equations, planning constraints, operation limits, and reliability constraints. The main problem can be written as in the following from the viewpoint of distribution companies.

\subsection{The main problem model}

\subsubsection{Objective function}

The investment, operation, maintenance, and reliability costs are included in the objective function as follows:

$$
\text { Minimize Cost }=\sum_{t \in \Omega_{t}} i n v_{t}+o p_{t}+m i_{t}+r e_{t} .
$$

where $i n v_{t}, o p_{t}, m i_{t}$, and $r e_{t}$ are calculated by Eqs. (2)(5), as shown in Box I.

- Investment Cost (IC): This term is presented in Eq. (2) including two parts. The first part refers to investment cost of the elements connected to two buses such as line, station transformer, and protection device such as switches that are connected to lines as series. The second part is related to the investment cost of the elements connected to bus such as DG and custom power device (capacitor, DSTTCOM);

- Operation Cost (OC): In this paper, the conventional power plant and DG meet the demand energy of loads. Hence, the operation cost that refers to fuel cost of these elements is written in Eq. (3);

- Maintenance Cost (MC): This term in Eq. (4) includes two parts. The first part refers to the maintenance cost of elements that are between two buses, while the second part is related to those connected to the bus;

- Reliability Cost ( $R C$ ): This term presented in Eq. (5) consists of the costs of four reliability indices. Costs of SAIDI and SAIFI are defined for power system, while costs of CID and CIF are defined for each network bus.

\subsubsection{The constraints of elements connected between two buses}

In this paper, the lines, station transformer, and protection device connected to the line as series belong to this group. Hence, the terms of $C^{A, S}$ and $C^{0 m, A m, S m}$ are considered for the line with protection device or station transformer costs. Finally, these constraints are written as follows:

$$
\begin{aligned}
P L_{(n, j), l, t}^{m}= & g_{(n, j)}^{m}\left(V_{n, l, t}\right)^{2}-V_{n, l, t} V_{j, l, t} \\
& \left\{g_{(n, j)}^{m} \cos \left(\theta_{n, l, t}-\theta_{j, l, t}\right)\right. \\
& \left.+b_{(n, j)}^{m} \sin \left(\theta_{n, l, t}-\theta_{j, l, t}\right)\right\} x_{(n, j), t}^{m} \\
\forall(n, j), l, t, m=0, A, S, & \\
Q L_{(n, j), l, t}^{m}= & -b_{(n, j)}^{m}\left(V_{n, l, t}\right)^{2}+V_{n, l, t} V_{j, l, t} \\
& \left\{b_{(n, j)}^{m} \cos \left(\theta_{n, l, t}-\theta_{j, l, t}\right)\right.
\end{aligned}
$$




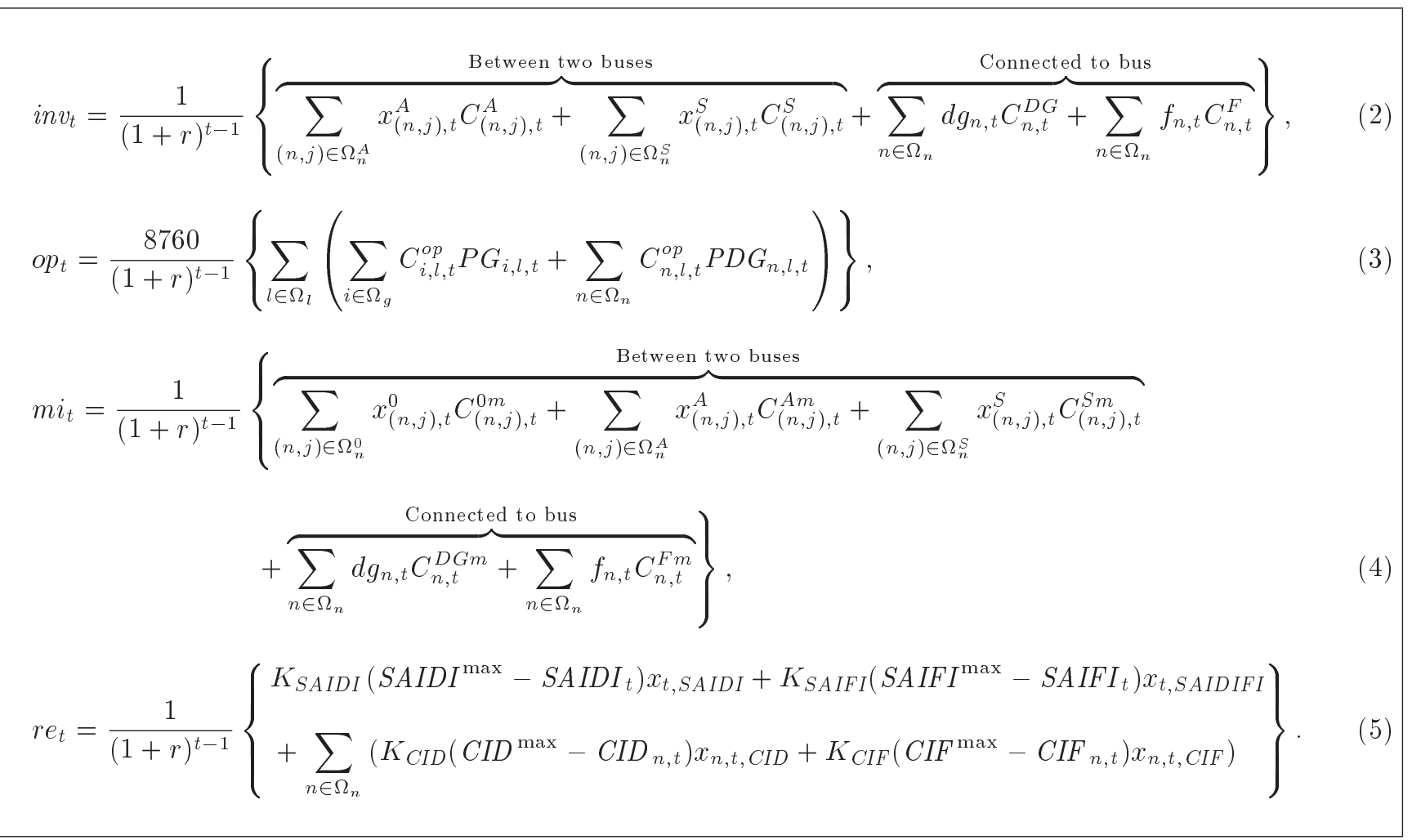

$$
\begin{gathered}
\left.-g_{(n, j)}^{m} \sin \left(\theta_{n, l, t}-\theta_{j, l, t}\right)\right\} x_{(n, j), t}^{m} \\
\forall(n, j), l, t, m=0, A, S, \\
\left(P L_{(n, j), l, t}^{m}\right)^{2}+\left(Q L_{(n, j), l, t}^{m}\right)^{2} \leqslant\left(S L_{(n, j)}^{m, \max }\right)^{2} \\
\forall(n, j), l, t, m=0, A, S, \\
x_{(n, j), t}^{0}+x_{(n, j), t}^{S} \leq 1 \quad \forall(n, j), t, \\
x_{(n, j), t}^{m} \geq x_{(n, j), t-1}^{m} \quad \forall(n, j), t, m=A, S .
\end{gathered}
$$

The active and reactive power flows of lines or station transformer are formulated in Eqs. (6) and (7). The limit of apparent power of lines or station transformer is given in Relation (8). As demonstrated by Relation (9), it is not possible to simultaneously have both existent and replacement elements at the same time. It is noted that if $x=1$ at $t$, then it should be one in future years. This statement is presented in Relation (10), which is reiterated in the case of $A$ and $S$ indices.

\subsection{3. $D G$ constraints}

In this paper, it is assumed that each bus includes DG. Also, it is noted that the selection of DG depends on investment, operation, and maintenance costs and reliability index. Hence, different variables of DGs should be considered in investment, operation, and maintenance costs equations and power balance equations. Another constraint of DG is given in Eq. (11) [21]:

$$
\begin{aligned}
& \left(P D G_{n, l, t}\right)^{2}+\left(Q D G_{n, l, t}\right)^{2} \leq d g_{n, t}\left(S D G_{n}^{\max }\right)^{2} \\
& \forall n, l, t .
\end{aligned}
$$

This equation presents the limit of apparent power of DG. Of note, the binary variable of $d g$ determines whether or not the interested DG can be selected. In other words, the $\mathrm{DG}$ is to be selected if $d g=1$; otherwise, the DG is not selected.

\subsubsection{Distribution automation constraints}

The distribution automation system includes protection element and custom power device. The protection elements are on the lines or station transformer, and the constraints are given in Relations (6)-(10). Selection of a custom power device depends on investment and maintenance costs and network and reliability indices. Hence, the different variables of the custom power device should be presented in investment and maintenance costs and power balance equations. Another constraint of customer power device is given in Eq. (12) [22]:

$$
\begin{aligned}
& Q F_{n, l, t}(\leqslant \text { or }=) f_{n, t} \sqrt{\left.\left(S F_{n}^{\max }\right)^{2}-\left(1-\eta_{n}\right) S F_{n}^{\max }\right)^{2}} \\
& \forall n, l, t .
\end{aligned}
$$


This equation indicates the reactive power limit of the custom power device. It is noted that the binary variable of $f$ determines the selection of the custom power device. In other words, the custom power device will be selected if $f=1$; otherwise, the custom power device will not be selected. Also, the term $\left(1-\eta_{n}\right) S F_{n}^{\max }$ is considered as active power loss of a custom power device.

\subsubsection{Generating units limit}

The limit of generation units is determined using Relation (13):

$$
\left(P G_{i, l, t}\right)^{2}+\left(Q G_{i, l, t}\right)^{2} \leq\left(S G_{i}^{\max }\right)^{2} \quad \forall i, l, t .
$$

\subsubsection{Voltage limit}

The voltage limit is obtained through Relation (14):

$$
V_{n}^{\min } \leq V_{n, l, t} \leq V_{n}^{\max } \quad \forall n, l, t .
$$

The maximum value of voltage is considered 1.05 per unit, and the minimum values of voltage are 0.95 and 0.9 for transmission and distribution networks, respectively.

\subsubsection{Radial distribution network constraints}

In general, the distribution network is considered as radial. In radial distribution networks, the number of buses is equal to that of lines + one. This statement is given as follows:

$$
\begin{array}{cc}
\sum_{m=0, A, S} x_{(n, j), t}^{m}=N_{(n, j), t}^{\text {line }} & \forall(n, j), t, \\
y_{(n, j), t} \leq N_{(n, j), t}^{\text {line }} \leq n_{(n, j), t}^{\max } y_{(n, j), t} & \forall(n, j), t, \\
\sum_{(n, j) \in \Omega_{n}} A D_{(n, j)} y_{(n, j), t}=N D-1 & \forall(n, j), t .
\end{array}
$$

In Eq. (15), the number of elements between buses $n$ and $j$ is calculated. The number of elements is between one and $n^{\max }$; hence, $y=1$. However, if the number of elements is equal to zero, $y=0$. Finally, the radial distribution network constraint is presented in Eq. (17). $A D$ is equal to one if the element between $(n, j)$ belongs to the distribution network and is equal to zero if the element between $(n, j)$ belongs to the transmission network.

The proposed model can be considered as the model of meshed sub-transmission/distribution network upon removing the radial distribution network constraints, i.e., Eqs. (15) to (17).

\subsubsection{Reliability constraints}

The reliability constraints are as follows [23]:

$$
\lambda_{(n, j), t}=\lambda_{(n, j), h=1, t} z_{(n, j), h=1, t}
$$

$$
-\sum_{h=2}^{\substack{\max \\(n, j), t}} \Delta \lambda_{(n, j), h, t}\left(z_{(n, j), h, t}-z_{(n, j), h-1, t}\right)
$$$$
\forall(n, j), h, t,
$$

$$
u_{(n, j), t}=u_{(n, j), h=1, t} z_{(n, j), h=1, t}
$$$$
-\sum_{h=2}^{\substack{\max \\(n, j), t}} \Delta u_{(n, j), h, t}\left(z_{(n, j), h, t}-z_{(n, j), h-1, t}\right)
$$

$$
\forall(n, j), h, t,
$$

$z_{(n, j), h, t}=\sum_{p=1}^{h} y_{(n, j), p, t}^{A} \quad \forall(n, j), h, t$,

$y_{(n, j), p+1, t}^{A} \leq y_{(n, j), p, t}^{A} \quad \forall(n, j), p, t$,

$y_{(n, j), p, t}^{A} \leq \sum_{\tau=1}^{t} x_{(n, j), l, \tau}^{A} \quad \forall(n, j), p, t$,

$C I F_{n, t}=S_{\lambda} \lambda_{(n, j), t}$

$\forall n, t$,

$C I D_{n, t}=S_{\lambda} u_{(n, j), t}$

$\forall n, t$,

$S A I F I_{t}=\frac{\sum_{n \in \varphi_{n}} C I F_{n, t}}{\text { total load number }} \quad \forall t$,

$S A I D I_{t}=\frac{\sum_{n \in \varphi_{n}} C I D_{n, t}}{\text { total load number }} \quad \forall t$,

$\left\{\begin{array}{l}C I D_{n, t} \leq C I D^{\max }\left(1-x_{n, t, C I D}\right) \\ C I D_{n, t} \geq C I D^{\max } x_{n, t, C I D}\end{array} \quad \forall n, t\right.$

$\left\{\begin{array}{l}C I F_{n, t} \leq C I F^{\max }\left(1-x_{n, t, C I F}\right) \\ C I F_{n, t} \geq C I F^{\max } x_{n, t, C I F}\end{array} \quad \forall n, t\right.$,

$\left\{\begin{array}{l}S A I D I_{t} \leq S A I D I^{\max }\left(1-x_{t, S A I D I}\right) \\ S A I D I_{t} \geq S A I D I^{\max } x_{t, S A I D I}\end{array} \quad \forall t\right.$

$$
\left\{\begin{array}{l}
\text { SAIFI }_{t} \leq S A I F I^{\max }\left(1-x_{t, S A I F I}\right) \\
\text { SAIFI }_{t} \geq S A I F I^{\max } x_{t, S A I F I}
\end{array} \quad \forall t,\right.
$$

Eqs. (18) and (19) calculate the failure rate and equivalent interruption duration time, and Eq. (20) shows the number of parallel circuits. Finally, the reliability indices are obtained through Eqs. (23)-(26) and the limitation of reliability indices is expressed in Eqs. (27)-(30). It is noted that the binary variable 
of $x$ is one if the reliability index is greater than its maximum. For example, if CID is less (more) than CID ${ }^{\text {max }}$, the cost of CID is (is not) zero. Therefore, the binary variable of $x C I D$ based on $\mathrm{Eq}$. (27) is zero (one). The CID cost is (is not) removed in Eq. (5) based on the value of $x x C I D$. Finally, Relations (27)-(30) are used in this paper for obtaining different $x$ values. Moreover, the elements of matrix $S_{\lambda}$ are equal to one if line $(n, j)$ impacts on load bus $n$.

\subsubsection{Power balance constraints}

These constraints for active and reactive power balance are presented in Eqs. (31) and (32). Also, the voltage angle of the reference bus is expressed in Eq. (33):

$$
\begin{aligned}
P D G_{n, l, t} & +\sum_{i \in \Omega_{g}} A G_{i, n} P G_{i, l, t} \\
& +\sum_{m=0, A, S} \sum_{(n, j) \in \Omega_{n}^{m}} A L_{(n, j)}^{m} P L_{(n, j), l, t}^{m} \\
& =P D_{n, l, t} \quad \forall n, l, t \\
Q D G_{n, l, t} & +Q F_{n, l, t}+\sum_{i \in \Omega_{g}} A G_{i, n} Q G_{i, l, t} \\
& +\sum_{m=0, A, S} \sum_{(n, j) \in \Omega_{n}^{m}} A L_{(n, j)}^{m} Q L_{(n, j), l, t}^{m} \\
= & Q D_{n, l, t} \quad \forall n, l, t, \\
& \forall n=r e f, l, t .
\end{aligned}
$$

\subsection{The MILP model}

The optimization problem is Mixed Integer Non-Linear Programming (MINLP) model. Also, this model is non-convex due to Eqs. (6) and (7). Hence, it is predicted that the problem is trapped at a locally optimal point and also, the calculation speed of this model is very low. Finally, it is possible that this problem becomes infeasible for large networks with a large number of elements, because the proposed problem is a special instance of a knapsack problem, which is an NP-hard formulation [24,25]. Therefore, this study presents the Mixed Integer Linear Programming (MILP) model, which is equal to the main problem model in terms of negligible error.

In the main problem model, Eqs. (6)-(8), (5), (11), (13), (18), and (19) are the mixed integer nonlinear. For linearization of Eqs. (6) and (7), the voltage is considered to be close to 1 per unit, and the voltage angle difference between two buses or across a line is lower than 6 degrees. Hence, the voltage is expressed as $1+\Delta V$ in which $\Delta V$ is much lower than 1 and terms of $\Delta V^{2}$ and $\Delta V \times\left(\theta_{i}-\theta_{j}\right)$ are close to zero, hence negligible. Finally, the linear Eqs. (6) and (7) are given as follows [26,27]:

$$
\begin{gathered}
P L_{(n, j), l, t}^{m}=\left\{g_{(n, j)}^{m}\left(\Delta V_{n, l, t}-\Delta V_{j, l, t}\right)\right. \\
\left.\quad-b_{(n, j)}^{m}\left(\theta_{n, l, t}-\theta_{j, l, t}\right)\right\} x_{(n, j), t}^{m} \\
\forall(n, j), l, t, m=0, A, S, \\
Q L_{(n, j), l, t}^{m}=-\left\{b_{(n, j)}^{m}\left(\Delta V_{n, l, t}-\Delta V_{j, l, t}\right)\right. \\
\left.\quad+g_{(n, j)}^{m}\left(\theta_{n, l, t}-\theta_{j, l, t}\right)\right\} x_{(n, j), t}^{m} \\
\forall(n, j), l, t, m=0, A, S .
\end{gathered}
$$

Eqs. (34) and (35) still remain as mixed integer nonlinear due to multiplication between $x$ and the righthand side of the mentioned equations. Based on these equations, $P L, Q L \neq 0$ if $x=1$ and $P L, Q L=0$ if $x=0$. This statement can be written as follows:

$$
\begin{aligned}
&-M\left(1-x_{(n, j), t}^{m}\right) \leq P L_{(n, j), l, t}^{m} \\
&-\left\{g_{(n, j)}^{m}\left(\Delta V_{n, l, t}-\Delta V_{j, l, t}\right)-b_{(n, j)}^{m}\left(\theta_{n, l, t}-\theta_{j, l, t}\right)\right\} \\
& \leq M\left(1-x_{(n, j), t}^{m}\right) \\
& \forall(n, j), l, t, m=0, A, S, \\
&-M\left(1-x_{(n, j), t}^{m} \leq Q L_{(n, j), l, t}^{m}\right. \\
& \quad+\left\{b_{(n, j)}^{m}\left(\Delta V_{n, l, t}-\Delta V_{j, l, t}\right)+g_{(n, j)}^{m}\left(\theta_{n, l, t}-\theta_{j, l, t}\right)\right\} \\
& \quad \leq M\left(1-x_{(n, j), t}^{m}\right) \\
& \forall(n, j), l, t, m=0, A, S, \\
&\left(P L_{(n, j), l, t}^{m}\right)^{2}+\left(Q L_{(n, j), l, t}^{m}\right)^{2} \leq x_{(n, j), t}^{m}\left(S L_{(n, j)}^{m, \max }\right)^{2} \\
& \forall(n, j), l, t, m=0, A, S .
\end{aligned}
$$

Based on Relations (36)-(38), $x=1$; thus, $P L, Q L \neq$ 0 . However, $P L, Q L=0$ if $x=0$. Relations (11), (13), and (38) are circular inequalities. The linear equations of these constraints based on [28] represent Relations (39)-(41):

$$
\begin{aligned}
& P L_{(n, j), l, t}^{m} \cos (k \Delta \alpha)+Q L_{(n, j), l, t}^{m} \sin (k \Delta \alpha) \\
& \leq x_{(n, j), t}^{m} S L_{(n, j)}^{m, \max } \quad \forall(n, j), l, t, k, m=0, A, S,
\end{aligned}
$$

$$
\begin{aligned}
& P D G_{n, l, t} \cos (k \Delta \alpha)+Q D G_{n, l, t} \sin (k \Delta \alpha) \\
& \leq d g_{n, t} S D G_{n}^{\max } \quad \forall n, l, t, k, \\
& P G_{i, l, t} \cos (k \Delta \alpha)+Q G_{i, l, t} \sin (k \Delta \alpha) \leq S G_{i}^{\max } \\
& \forall i, l, t, k,
\end{aligned}
$$


where $\Delta \alpha$ is the angle deviation and $k$ denotes the index of linearization segments of the circular equation. It is noted that $\Delta \alpha$ is equal to $360 / n_{k}$ in which $n_{k}$ is the number of linearization segments of the circular equation, hence $k=\left\{1,2, \cdots, n_{k}\right\}$. In addition, Eqs. (5), (18), and (19) include the multiplication contiguous variable and binary variable. Linearization of this equation is done through Eq. (42):

$$
\begin{aligned}
& a \times b=c \quad \forall a_{\min } \leq a \leq a_{\max }, \\
& b=1,2,3, \cdots, n \\
& \Longleftrightarrow\left\{\begin{array}{l}
b=\sum_{i=1}^{n} i \times x_{i} \quad \forall x \in\{0,1\} \\
c=\sum_{i=1}^{n} i \times z_{i} \quad \forall z_{i}=a \times x_{i} \\
a_{\min }\left(1-x_{i}\right) \leq z_{i}-a \leq a_{\max }\left(1-x_{i}\right) \\
a_{\min } x \leq z_{i} \leq a_{\max } x
\end{array}\right.
\end{aligned}
$$

Finally, the MILP model is demonstrated by Eqs. (43) and (44):

$$
\min \text { Cost }=\sum_{t \in \Omega_{t}} i n v_{t}+o p_{t}+m i_{t}+r e_{t} .
$$

Subject to:

$$
\begin{aligned}
& (2)-(4),(9),(10),(12),(14)-(17),(20)-(33), \\
& (36),(37),(39)-(42) .
\end{aligned}
$$

\section{Numerical results and discussion}

\subsection{Case study}

The proposed problem model was studied based on a 6-bus transmission and sub-transmission network (as depicted in Figure 1) and a 10-bus or two-feeder radial distribution network (as depicted in Figure 2). The data of transmission, sub-transmission, and distribution networks are presented in Tables 2 to 5 , respectively. In these tables, $n^{0}$ is equal to the number of equipment items at the beginning of planning. There is a transmission substation with $230 / 138 \mathrm{kV}$ transformer, which is between rb1 and st3 buses. Also, the distribution network connects to transmission network with $138 / 13.8 \mathrm{kV}$ transformer, which is between st2d17 buses.

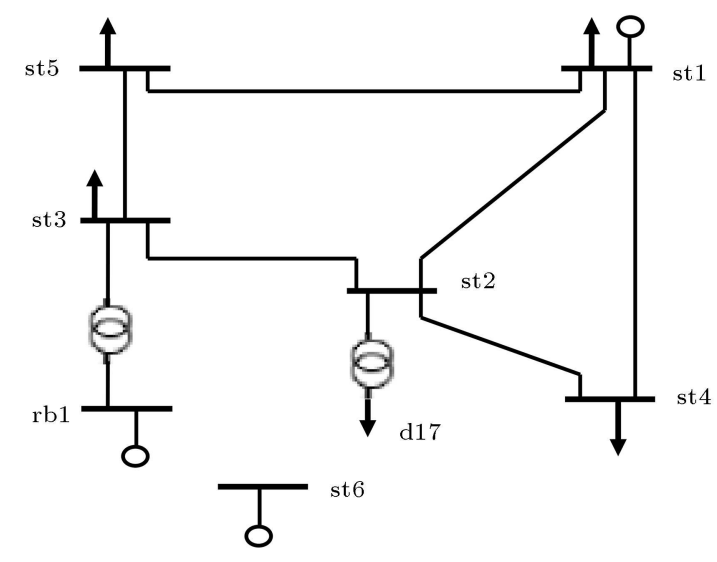

Figure 1. Transmission and sub-transmission network.

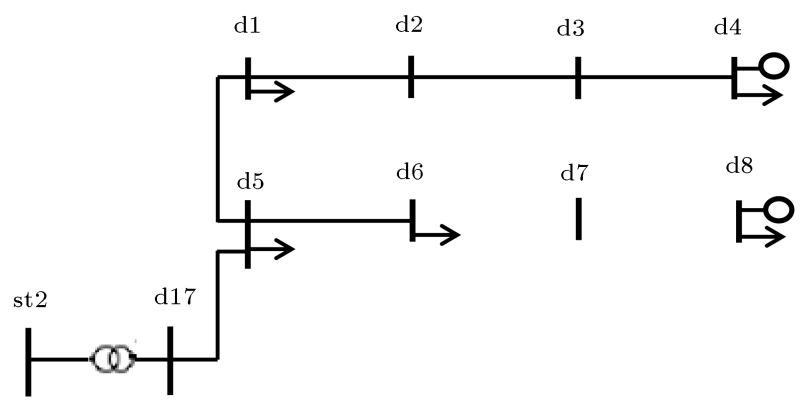

Figure 2. Distribution network.

The energy price for generation unit and DGs is considered to be 4.2 and $2.5 \$ / \mathrm{MW}$ year, respectively. Moreover, the generation units are connected to rb1, st1, and st 6 with capacities of 120, 5, and 60 MVA, respectively. In addition, this study considers that DG can be connected to $\mathrm{d} 8$ and $\mathrm{d} 4$ buses with capacities of 2.4 and $4.8 \mathrm{MVA}$ and investment costs of 0.04 and $0.08 \mathrm{M} \$$, respectively. Also, it considers that there are two fixed capacitor banks that can be connected to $\mathrm{d} 8$ and $\mathrm{d} 4$ buses with capacities of 1.2 and 2.4 MVAr and investment costs of 0.02 and $0.04 \mathrm{M} \$$, respectively. The maximum voltage is equal to 1.05 per unit, while the minimum voltage for transmission and distribution networks is 0.95 and 0.9 per unit, respectively.

The value of active load is presented in Table 6 . Also, this paper considers that the power factor is equal to 0.85 , which is the same for all loads. Moreover, there are three levels for load in one year named low,

\begin{tabular}{|c|c|c|c|c|c|c|c|c|c|c|}
\hline \multirow{2}{*}{ From-to } & \multirow{2}{*}{$n^{0}$} & \multirow{2}{*}{$\begin{array}{c}R^{0} \\
(\mathrm{pu})\end{array}$} & \multirow{2}{*}{$\begin{array}{c}X^{\mathbf{0}} \\
(\mathrm{pu})\end{array}$} & \multirow{2}{*}{$\begin{array}{c}S^{\max } \\
(\mathrm{MVA})\end{array}$} & \multicolumn{3}{|c|}{$n^{\max }$} & \multicolumn{3}{|c|}{$C^{A}(\mathrm{M} \$)$} \\
\hline & & & & & $t=1$ & $t=2$ & $t=3$ & $t=1$ & $t=2$ & $t=3$ \\
\hline rb1-st3 & 1 & 0 & 0.1 & 35 & 2 & 2 & 3 & 6 & 6.3 & 6.62 \\
\hline
\end{tabular}
medium, and high levels. The load coefficients at the three levels are equal to $0.5,0.75$, and 1 , respectively. Moreover, the reliability factors including $C I D^{\max }$, $C{ }^{\max }, S A I D I^{\max }$, and $S A I F I^{\max }$ are equal to 4

Table 2. Transmission equipment's data. 
Table 3. Sub-transmission network data.

\begin{tabular}{|c|c|c|c|c|c|c|c|c|c|c|c|c|c|c|}
\hline \multirow[t]{2}{*}{ From-to } & \multirow[t]{2}{*}{$n^{0}$} & \multirow{2}{*}{$\begin{array}{c}R^{\mathbf{o}} \\
(\mathrm{pu})\end{array}$} & \multirow{2}{*}{$\begin{array}{c}\boldsymbol{X}^{\mathbf{0}} \\
(\mathrm{pu})\end{array}$} & \multirow{2}{*}{$\begin{array}{c}S^{\max } \\
(\mathrm{MVA})\end{array}$} & \multicolumn{3}{|c|}{$n^{\max }$} & \multicolumn{3}{|c|}{$C^{A}(\mathrm{M} \$)$} & \multicolumn{2}{|c|}{$\begin{array}{c}\text { Replacement } \\
\text { option } \\
S=1\end{array}$} & \multicolumn{2}{|c|}{$\begin{array}{c}\text { Replacement } \\
\text { option } \\
S=2 \\
\end{array}$} \\
\hline & & & & & $t=1$ & $t=2$ & $t=3$ & $t=1$ & $t=2$ & $t=3$ & $\begin{array}{c}S^{\max } \\
(\mathrm{MVA})\end{array}$ & $\begin{array}{c}C^{S} \\
(\mathrm{M} \$)\end{array}$ & $\begin{array}{c}S^{\max } \\
(\mathrm{MVA})\end{array}$ & $\begin{array}{c}C^{S} \\
(\mathrm{M} \$)\end{array}$ \\
\hline st1-2 & 1 & 0.04 & 0.4 & 10 & 2 & 2 & 3 & 4 & 4.2 & 4.41 & & & & \\
\hline st1-4 & 1 & 0.06 & 0.6 & 8 & 2 & 2 & 3 & 6 & 6.3 & 6.62 & & & & \\
\hline st1-5 & 1 & 0.02 & 0.2 & 10 & 2 & 2 & 3 & 2 & 2.1 & 2.21 & & & & \\
\hline st2-3 & 1 & 0.01 & 0.1 & 10 & & & & & & & 16 & 0.6 & 20 & 1 \\
\hline st 2-4 & 1 & 0.04 & 0.4 & 10 & 2 & 2 & 3 & 4 & 4.2 & 4.41 & & & & \\
\hline st $2-6$ & 0 & 0.01 & 0.1 & 10 & 4 & 4 & 5 & 3 & 3.15 & 3.31 & & & & \\
\hline st3-5 & 1 & 0.05 & 0.5 & 10 & 2 & 2 & 3 & 2 & 2.1 & 2.21 & & & & \\
\hline st4-6 & 0 & 0.01 & 0.1 & 10 & 2 & 2 & 3 & 3 & 3.15 & 3.31 & & & & \\
\hline
\end{tabular}

Table 4. Sub-transmission/distribution substation equipment data.

\begin{tabular}{|c|c|c|c|c|c|c|c|c|c|c|}
\hline \multirow{2}{*}{ From-to } & \multirow{2}{*}{$n^{0}$} & \multirow{2}{*}{$\begin{array}{c}R^{\mathbf{o}} \\
(\mathrm{pu})\end{array}$} & \multirow{2}{*}{$\begin{array}{c}\boldsymbol{X}^{\mathbf{o}} \\
(\mathrm{pu})\end{array}$} & \multirow{2}{*}{$\begin{array}{c}S^{\max } \\
(\mathrm{MVA})\end{array}$} & \multicolumn{3}{|c|}{$n^{\max }$} & \multicolumn{3}{|c|}{$C^{A}(\mathrm{M} \$)$} \\
\hline & & & & & $t=1$ & $t=2$ & $t=3$ & $t=1$ & $t=2$ & $t=3$ \\
\hline st2-d17 & 1 & 0 & 0.2 & 16 & 2 & 2 & 3 & 0.6 & 0.63 & 0.662 \\
\hline
\end{tabular}

Table 5. Distribution network data.

\begin{tabular}{|c|c|c|c|c|c|c|c|c|c|c|c|c|c|c|c|}
\hline \multirow[t]{2}{*}{ From } & \multirow[t]{2}{*}{ To } & \multirow[t]{2}{*}{$n^{0}$} & \multirow{2}{*}{$\begin{array}{c}R^{0} \\
\left(10^{-4} \mathrm{pu}\right)\end{array}$} & \multirow{2}{*}{$\begin{array}{c}X^{\mathbf{0}} \\
\left(10^{-4} \mathrm{pu}\right)\end{array}$} & \multirow{2}{*}{$\begin{array}{c}S^{\max } \\
\text { (MVA) }\end{array}$} & \multicolumn{3}{|c|}{$n^{\max }$} & \multicolumn{3}{|c|}{$C^{A}(\mathrm{M} \$)$} & \multicolumn{2}{|c|}{$\begin{array}{c}\text { Replacement } \\
\text { option } \\
S=1\end{array}$} & \multicolumn{2}{|c|}{$\begin{array}{c}\text { Replacement } \\
\text { option } \\
S=2\end{array}$} \\
\hline & & & & & & $t=1$ & $t=2$ & $t=3$ & $t=1$ & $t=2$ & $t=3$ & $\begin{array}{c}S^{\max } \\
(\text { MVA) }\end{array}$ & $\begin{array}{c}C^{S} \\
(\mathrm{M} \$)\end{array}$ & $\begin{array}{c}S^{\max } \\
(\text { MVA) }\end{array}$ & $\begin{array}{c}C^{S} \\
(\mathrm{M} \$)\end{array}$ \\
\hline $\mathrm{d} 17$ & $\mathrm{~d} 5$ & 1 & 21 & 15 & 12 & 2 & 2 & 3 & 0.13 & 0.137 & 0.144 & & & & \\
\hline $\mathrm{d} 5$ & $\mathrm{~d} 1$ & 1 & 42 & 32 & 6 & & & & & & & 9.6 & 0.027 & 12 & 0.045 \\
\hline $\mathrm{d} 1$ & $\mathrm{~d} 2$ & 1 & 42 & 32 & 6 & 2 & 2 & 3 & 0.09 & 0.095 & 0.1 & & & & \\
\hline $\mathrm{d} 2$ & $\mathrm{~d} 3$ & 1 & 42 & 32 & 6 & 2 & 2 & 3 & 0.09 & 0.095 & 0.1 & & & & \\
\hline $\mathrm{d} 3$ & $\mathrm{~d} 4$ & 1 & 42 & 32 & 6 & 2 & 2 & 3 & 0.09 & 0.095 & 0.1 & & & & \\
\hline $\mathrm{d} 4$ & $\mathrm{~d} 8$ & 0 & 42 & 32 & 6 & 2 & 2 & 3 & 0.09 & 0.095 & 0.1 & & & & \\
\hline d6 & $\mathrm{d} 6$ & 1 & 42 & 32 & 6 & & & & & & & 9.6 & 0.027 & 12 & 0.045 \\
\hline d6 & $\mathrm{d} 7$ & 0 & 42 & 32 & 6 & 2 & 2 & 3 & 0.094 & 0.099 & 0.104 & & & & \\
\hline $\mathrm{d} 7$ & $\mathrm{~d} 8$ & 0 & 42 & 32 & 6 & 2 & 2 & 3 & 0.096 & 0.101 & 0.106 & & & & \\
\hline
\end{tabular}

Table 6. The value of active load in high level load.

\begin{tabular}{ccccccccc}
\hline \multirow{2}{*}{ Bus } & \multicolumn{3}{c}{ Active load (MW) } & \multirow{2}{*}{ Bus } & \multicolumn{3}{c}{ Active load (MW) } \\
\cline { 2 - 3 } & $\boldsymbol{t}=\mathbf{1}$ & $\boldsymbol{t}=\mathbf{2}$ & $\boldsymbol{t}=\mathbf{3}$ & & $\boldsymbol{t}=\mathbf{1}$ & $\boldsymbol{t}=\mathbf{2}$ & $\boldsymbol{t}=\mathbf{3}$ \\
\hline rb1 & & & & $\mathrm{d} 1$ & & 4.8 & 5.3 & 5.8 \\
st1 & 8 & 8.8 & 9.7 & $\mathrm{~d} 2$ & & & \\
st2 & & & & $\mathrm{d} 3$ & & & \\
st3 & 4 & 4.4 & 4.8 & $\mathrm{~d} 4$ & 4.8 & 5.3 & 5.8 \\
st4 & 16 & 17.6 & 19.4 & $\mathrm{~d} 5$ & 4.8 & 5.3 & 5.8 \\
st5 & 24 & 26.4 & 29.1 & & $\mathrm{~d} 6$ & 4.8 & 5.3 & 5.8 \\
st6 & & & & $\mathrm{d} 7$ & & & \\
d17 & & & & $\mathrm{d} 8$ & 4.8 & 5.3 & 5.8 \\
\hline
\end{tabular}


hours/year, 4 interruptions/year, 2 hours/year, and 4 interruptions/year, respectively [28].

\subsection{Results}

The proposed problem is applied to the case study of a test network using GAMS. 24 software. CPLEX and BONMIN solvers are employed for MILP and MINLP models, respectively [29].

In the following, the proposed framework in this paper will be investigated from different aspects: computational aspect, economic analysis, reliability, impacts of distribution automation:

1. Comparison between MINLP and MILP models: Table 7 expresses the results of the comparison between MINLP and MILP models. Based on this table, the calculation error between the two models for active and reactive powers is equal to about $3 \%$, and it is equal to about $0.5 \%$ for the angle and amplitude of voltage. Therefore, the calculation error of different variables between the two models almost is very low. Also, the calculation time of MINLP model is very long, because the number of binary variables is large and the equations are non-linear and non-convex. Hence, it is predicted that this model does not reach a feasible solution in the large network. However, the calculation time is short for the MILP model. Therefore, the MILP model is suitable, because it has low calculation time and error;

2. Investigation of economic results: The results of this section are given in Tables $8-10$. Table 8 shows that the investment characterizes the investment cost and number of investment circuits. According to this table, 1 high voltage post (rb1-st3), 1 medium voltage post (st2-d17), 6 transmission lines, 6 distribution lines, 2 DGs, and 2 capacitors are added to the test network in the first year. It is noted that the investment cost of each circuit is low in the first year based on Tables 2-5. Hence, the new circuits are added to the test network in the first year. Moreover, the total investment cost is equal to $23.396 \mathrm{M} \$$ : $22 \mathrm{M} \$$ for transmission network and $1.396 \mathrm{M} \$$ for distribution network.

Table 9 shows the characterization of replacement cost and replacement option. This table

Table 9. Replacement characterization.

\begin{tabular}{ccc}
\hline \multirow{2}{*}{ Elements } & \multicolumn{2}{c}{ Replacement option } \\
\cline { 2 - 3 } & $\boldsymbol{S}=\mathbf{1}$ & $\boldsymbol{S}=\mathbf{2}$ \\
\hline st2-3 & 0 & 1 \\
d5-1 & 1 & 0 \\
d $5-6$ & 0 & 1 \\
Replacement cost $(\mathrm{M} \$)$ & 0.027 & 1.045 \\
\hline
\end{tabular}

Table 7. Comparison between MINLP and MILP models.

\begin{tabular}{lccc}
\hline \multicolumn{1}{c}{ Cases } & MINLP & MILP & Deviation (\%) \\
\hline Total active power generation (MW) & 78.1 & 75.9 & 2.81 \\
Total reactive power generation (MVAr) & 50.76 & 49.34 & 2.79 \\
Mean of voltage amplitude (pu) & 0.963 & 0.959 & 0.415 \\
Mean of voltage angle (pu) & -0.092 & 0.09206 & -0.652 \\
Calculation time (s) & 3842 & 971 & 74.72 \\
\hline
\end{tabular}

Table 8. Investment characterization.

\begin{tabular}{|c|c|c|c|c|c|c|c|}
\hline \multirow{2}{*}{ Elements } & \multicolumn{3}{|c|}{ Investment number } & \multirow{2}{*}{ Elements } & \multicolumn{3}{|c|}{ Investment number } \\
\hline & $t=1$ & $t=2$ & $t=3$ & & $t=1$ & $t=2$ & $t=3$ \\
\hline rb1-st3 & 1 & 0 & 0 & $\mathrm{~d} 2-3$ & 0 & 0 & 0 \\
\hline st1-2 & 0 & 0 & 0 & $\mathrm{~d} 3-4$ & 0 & 0 & 0 \\
\hline st1-4 & 0 & 0 & 0 & $\mathrm{~d} 4-8$ & 0 & 0 & 0 \\
\hline st1-5 & 0 & 0 & 0 & $\mathrm{~d} 6-7$ & 2 & 0 & 0 \\
\hline st2-4 & 0 & 0 & 0 & $\mathrm{~d} 7-8$ & 2 & 0 & 0 \\
\hline st $2-6$ & 2 & 0 & 0 & DG4 & 1 & 0 & 0 \\
\hline st3-5 & 2 & 0 & 0 & DG8 & 1 & 0 & 0 \\
\hline st4-6 & 2 & 0 & 0 & Cap4 & 1 & 0 & 0 \\
\hline st2-d17 & 1 & 0 & 0 & Cap8 & 1 & 0 & 0 \\
\hline $\mathrm{d} 17-5$ & 2 & 0 & 0 & Total & 18 & 0 & 0 \\
\hline $\mathrm{d} 1-2$ & 0 & 0 & 0 & Investment cost $(\mathrm{M} \$)$ & 23.396 & 0 & 0 \\
\hline
\end{tabular}


Table 10. Maintenance and operation costs.

\begin{tabular}{|c|c|c|c|c|c|}
\hline Elements & Number & $\begin{array}{l}\text { Capacity } \\
\text { (MVA) }\end{array}$ & $\begin{array}{c}\text { Maintenance rate } \\
(\$ / M V A)\end{array}$ & $\begin{array}{l}\mathrm{MC} \\
(\mathrm{M} \$)\end{array}$ & $\begin{array}{c}\mathrm{OC} \\
(\mathrm{M} \$)\end{array}$ \\
\hline rb1-st3 & 2 & 35 & 8000 & 0.56 & 0 \\
\hline st1-2 & 1 & 10 & 5000 & 0.05 & 0 \\
\hline st1-4 & 1 & 8 & 5000 & 0.04 & 0 \\
\hline st1-5 & 1 & 10 & 5000 & 0.05 & 0 \\
\hline st $2-3$ & 1 & 20 & 5000 & 0.10 & 0 \\
\hline st 2-4 & 1 & 10 & 5000 & 0.05 & 0 \\
\hline st 2-6 & 2 & 10 & 5000 & 0.10 & 0 \\
\hline st $3-5$ & 3 & 10 & 5000 & 0.15 & 0 \\
\hline st $4-6$ & 2 & 10 & 5000 & 0.10 & 0 \\
\hline grb1 & 1 & 120 & 9000 & 1.08 & 6.07 \\
\hline g1 & 1 & 5 & 4000 & 0.02 & 0.33 \\
\hline g6 & 1 & 60 & 7000 & 0.42 & 4.41 \\
\hline st $2-d 17$ & 2 & 16 & 5000 & 0.16 & 0 \\
\hline $\mathrm{d} 17-5$ & 3 & 12 & 2000 & 0.072 & 0 \\
\hline $\mathrm{d} 5-1$ & 1 & 9.6 & 2000 & 0.0192 & 0 \\
\hline $\mathrm{d} 1-2$ & 1 & 6 & 2000 & 0.012 & 0 \\
\hline $\mathrm{d} 2-3$ & 1 & 6 & 2000 & 0.012 & 0 \\
\hline d3-4 & 1 & 6 & 2000 & 0.012 & 0 \\
\hline $\mathrm{d} 4-8$ & 0 & 0 & 2000 & 0 & 0 \\
\hline $\mathrm{d} 5-6$ & 1 & 12 & 2000 & 0.024 & 0 \\
\hline$d 6-7$ & 2 & 6 & 2000 & 0.024 & 0 \\
\hline $\mathrm{d} 7-8$ & 2 & 6 & 2000 & 0.024 & 0 \\
\hline DG4 & 1 & 4.8 & 2500 & 0.012 & 0.31 \\
\hline DG8 & 1 & 2.4 & 1200 & 0.0028 & 0.16 \\
\hline Cap4 & 1 & 2.4 & 300 & 0.00072 & 0 \\
\hline Cap8 & 1 & 1.2 & 200 & 0.00024 & 0 \\
\hline Total & 35 & - & - & 3.095 & 11.2 \\
\hline
\end{tabular}

shows 1 transmission line with Option 2 and 2 distribution lines with options 1 and 2 replaced in the test network. The replacement cost for distribution and transmission networks is equal to $0.072 \mathrm{M} \$$ and $1 \mathrm{M} \$$, respectively. In addition, maintenance and operation costs are given in Table 10. It should be noted that maintenance cost is equal to:

Maintenance cost of each circuit $=($ Number

$\times$ Capacity $\times$ Maintenance rate) of circuit.

Finally, the total maintenance cost is equal to 3.095 $\mathrm{M} \$$ such that a high percentage of this cost is for the transmission network and low percentage of this cost for the distribution network. Also, the operation cost of the proposed problem is equal to 11.2 $\mathrm{M} \$$ : $10.71 \mathrm{M} \$$ and $0.49 \mathrm{M} \$$ for transmission and distribution networks, respectively;

3. Investigation of technical results: The results of this section are given in Table 11. Based on this table, the mean voltage of the transmission network is equal to 1.01 per unit and the low voltage of this network is 0.98 per unit. This study considers no voltage controlled (PV) bus in the proposed problem. Hence, voltage in each bus can be increased to 1.05 per unit. In addition, the mean and low voltages in the distribution network are equal to 0.926 and 0.906 per unit, respectively. Accordingly, for the sake of enhancing the reliability in the network, double lines of $\mathrm{d} 6-7$ and $\mathrm{d} 7-8$ should be should be constructed in the expansion planning.

According to Table 11, the active power loss in transmission networks is lower than reactive power loss in the distribution network, because the reactance of transmission lines is higher than the resistance of transmission lines. Also, the reactive power loss of distribution network is less than active power loss in the distribution network, 
Table 11. Technical characterization of network.

\begin{tabular}{|c|c|c|}
\hline \multirow{2}{*}{ Index } & \multicolumn{2}{|c|}{$t=3$} \\
\hline & Transmission network & Distribution network \\
\hline Mean of voltage amplitude (pu) & 1.01 & 0.926 \\
\hline Low of voltage amplitude (pu) & 0.98 & 0.906 \\
\hline Active power loss (MW) & 0.16 & 1.92 \\
\hline Reactive power loss (MVAr) & 1.53 & 1.21 \\
\hline
\end{tabular}

Table 12. Reliability characterization of network.

\begin{tabular}{|c|c|c|c|c|c|c|c|}
\hline \multirow{3}{*}{ Index } & \multicolumn{6}{|c|}{ Years } & \multirow{3}{*}{$\begin{array}{l}\text { Reliability cost } \\
\qquad(\mathrm{M} \$)\end{array}$} \\
\hline & \multicolumn{2}{|c|}{$t=1$} & \multicolumn{2}{|c|}{$t=2$} & \multicolumn{2}{|c|}{$t=3$} & \\
\hline & $\mathrm{TN}$ & DN & TN & DN & TN & DN & \\
\hline Mean of CID (h) & 0.72 & 1.65 & 0.72 & 1.65 & 0.72 & 1.65 & \\
\hline Mean of CIF (h) & 0.36 & 1.3 & 0.36 & 1.3 & 0.36 & 1.3 & 0 \\
\hline SAIDI (hour/year) & \multicolumn{2}{|c|}{1.25} & \multicolumn{2}{|c|}{1.25} & \multicolumn{2}{|c|}{1.25} & 0 \\
\hline SAIFI (interr/year) & \multicolumn{2}{|c|}{0.89} & \multicolumn{2}{|c|}{0.89} & \multicolumn{2}{|c|}{0.89} & \\
\hline
\end{tabular}

Note: TN: Transmission Network; DN: Distribution Network.

because the distribution line resistance is higher than distribution line reactance. Hence, the active power loss of the distribution network is less than active power loss of the transmission network. This statement is in reverse for reactive power loss;

4. Investigation of reliability results: The reliability characterization of the test network is given in Table 12. According to this table, the values of reliability indices such as CID and CIF in the transmission network are less than those in distribution network. Hence, the reliability of transmission network is higher than distribution network, because the number of generation units in the transmission network is more than that in the distribution network and transmission network is not radial. Moreover, the reliability indices are less than their maximum value. Therefore, the reliability cost is equal to zero;

5. Investigation of impacts of reducing maximum reliability indices: In this section, this paper considers that the maximum reliability indices such as $C I D^{\max }, C I F^{\max }, S A I D I^{\max }$, and $S A I F I^{\max }$ increase in value from zero to $100 \%$ with step $10 \%\left(0.4,0.4,0.2\right.$, and 0.2 for $C I D^{\max }, C I F^{\max }$, $S A I D I^{\mathrm{max}}$, and $S A I F I^{\mathrm{max}}$, respectively). The results of this section are presented in Figures 3 and 4 . Figure 3 shows the relationship between reliability cost and index. Based on this figure, the reliability cost will be reduced if the reliability index increases. Also, the reliability cost is equal to zero when reliability index is at $62 \%$ or $100 \%$, i.e., $C I D^{\max }, C I F^{\max }, S A I D I^{\max }$, and $S A I F I^{\max }$ are

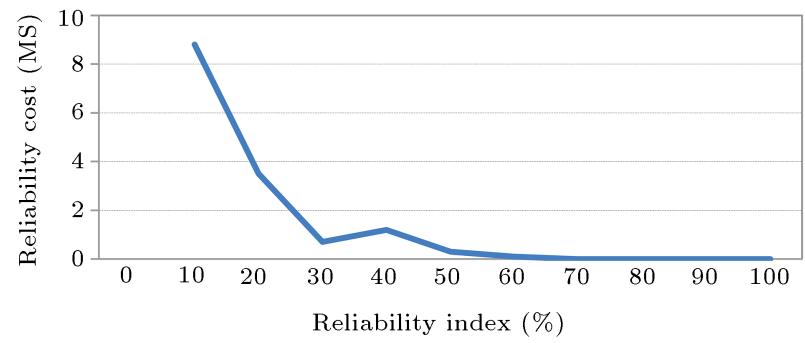

Figure 3. Relationship between reliability cost and index.

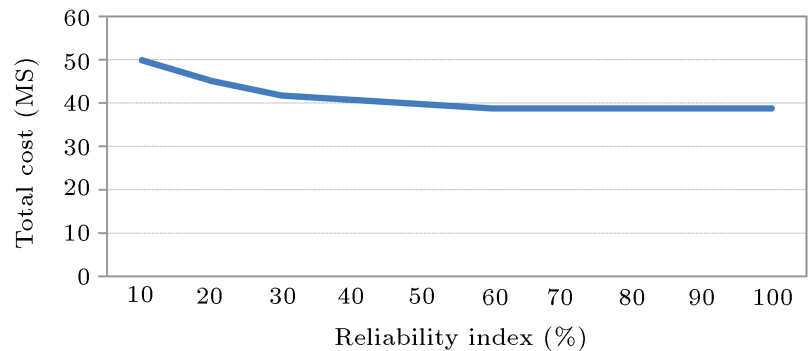

Figure 4. Relationship between total cost and reliability index.

equal to $(2.48,4),(2.48,4),(1.24,2)$, and $(1.24,2)$, respectively.

Figure 4 shows the relationship between total cost and reliability index. Based on this figure, the total cost is reduced if the reliability index increases. Also, the total cost is equal to $38.764 \mathrm{M} \$$ when reliability index is at $62 \%$ or $100 \%$;

6. Investigation of impacts of the DA: This section presents the impacts of DA in the power network. Hence, this study considers two cases in the power network: with and without DA. Also, CID ${ }^{\max }$, 
Table 13. Technical and reliability characterization of network.

\begin{tabular}{|c|c|c|c|}
\hline \multirow{2}{*}{ Case } & \multirow{2}{*}{ Index } & \multicolumn{2}{|c|}{$t=3$} \\
\hline & & TN & $\mathbf{D N}$ \\
\hline \multirow{9}{*}{ Without DA } & Mean of voltage amplitude (pu) & 1.011 & 0.921 \\
\hline & Low of voltage amplitude ( $\mathrm{pu}$ ) & 0.981 & 0.901 \\
\hline & Active power loss (MW) & 0.165 & 2.03 \\
\hline & Reactive power loss (MVAr) & 1.58 & 1.29 \\
\hline & Mean of CID (h) & 0.72 & 1.65 \\
\hline & Mean of CIF $(h)$ & 0.36 & 1.3 \\
\hline & SAIDI (hour/year) & \multicolumn{2}{|c|}{1.25} \\
\hline & SAIFI (interr/year) & \multicolumn{2}{|c|}{0.89} \\
\hline & Reliability cost $(\mathrm{M} \$)$ & \multicolumn{2}{|c|}{0} \\
\hline \multirow{9}{*}{ With DA } & Mean of voltage amplitude (pu) & 1.01 & 0.926 \\
\hline & Low of voltage amplitude (pu) & 0.98 & 0.906 \\
\hline & Active power loss (MW) & 0.16 & 1.92 \\
\hline & Reactive power loss (MVAr) & 1.53 & 1.21 \\
\hline & Mean of CID (h) & 0.72 & 0.8 \\
\hline & Mean of CIF (h) & 0.36 & 0.8 \\
\hline & SAIDI (hour/year) & \multicolumn{2}{|c|}{0.4} \\
\hline & SAIFI (interr/year) & \multicolumn{2}{|c|}{0.4} \\
\hline & Reliability cost $(\mathrm{M} \$)$ & \multicolumn{2}{|c|}{3.5} \\
\hline
\end{tabular}

$C F^{\max }$, SAIDI $^{\max }$, and SAIFI ${ }^{\max }$ are considered to be $0.8,0.8,0.4$, and 0.4 , respectively. The results of this section are given in Table 13. Based on this table, the DA is the reason why reliability and network indices are enhanced, because the custom power devices are used to enhance the network indices and switches are employed for the improvement of reliability indices.

\section{Conclusions}

This study presented sub-transmission and distribution network expansion planning with emphasis on DG and Distribution Automation (DA) as well as reliability indices. The objective function was to minimize the investment, operation, maintenance, and reliability costs. Also, the constraints of the proposed problem included $\mathrm{AC}$ power flow equations, reliability constraints, system operation and generation unit limits, DG equations, Distribution Automation (DA) constraints, and radial structure equations for the distribution network. The proposed base problem model was as Mixed Integer Non-linear Programming (MINLP), which is hard to solve. Hence, the equivalent mixed integer linear programing (MILP or MIP) model was used and it reached an optimal solution with lower computation burden. Based on the numerical results, the change in the distribution network was required in order to modify the transmission network. Also, the investment, operation, and maintenance costs were low in distribution and high in transmission networks. Also, the DA enhanced the network and reliability indices. Moreover, the total and reliability costs decreased following an increase in the reliability index.

In addition, some of the parameters associated with the proposed problem, such as load, were considered to be uncertain; hence, a robust model of the proposed problem is to be presented in future works. Also, future works may consider the operation of DA systems for fault management and network index management. Moreover, the MILP formulation makes it difficult to solve real network problems on a large scale and it has a long calculation time for this network. Hence, the MILP model with innovative methods can be a candidate for dealing with real networks in future works.

\section{Nomenclature}

Indices and sets

- $(n, j), t, l,(h, p), k$ : Indices of bus, time, load level, circuits in a connection, linearization segments of circular constraint

- $\Omega_{n}^{A}, \Omega_{n}^{S}, \Omega_{n}^{0}, \Omega_{n}$ : Sets of circuit or equipment candidates to be added and replaced, existing circuits or equipment, bus 
- $\Omega_{l}, \Omega_{g}, \Omega_{t}$ : Sets of load level, generation, time

\section{Variables}

- inv, op, mi, re: Investment, operation, maintenance, and reliability costs

- $x^{A}, x^{S}, x^{0}$ : Binary variable of circuit or equipment candidates to be added and replaced; existing circuits or equipment

- $d g, f$ : Binary variable of DG and capacitor candidates to be added

- SAIFI, SAIDI, CIF, CID: Reliability indexes

- $P L, P G, P D G$ : Active power of line, generation, and distributed generation

- $Q L, Q G, Q D G, Q F$ : Reactive power of line, generation, distributed generation, and capacitor

- $V, \Delta V, \theta$ : Voltage amplitude, voltage deviation, voltage angle

- $\quad \lambda, u, z$ : Failure rate, equivalent interruption duration time, parallel circuits number

\section{Constants}

- $C^{A}, C^{S}$ : Investment and replacement costs of line

- $C^{D G}, C^{F}$ : Investment cost of DG and capacitor

- $C^{A m}, C^{S m}, C^{0 m}$ : Maintenance cost of circuit or equipment candidates to be added and replaced, existing circuits or equipment

- $C^{D G m}, C^{F m}$ : Maintenance cost of DG and capacitor

- $C^{o p}$ : Operation price

- $K$ : Reliability indexes price

- $\quad g, b$ : Line conductance and susceptance

- $S G^{\max }, S L^{\max }, S D G^{\max }, S F^{\max }$ : Maximum capacity of generation, line, DG and capacitor

- $\eta$ : Efficiency of capacitor

- $V^{\text {max }}, V^{\text {min }}:$ Maximum and minimum voltages

- $n^{\max }:$ Maximum number of lines

- ND: Number of bus distribution networks

- $\Delta \lambda, \Delta u$ : Deviation of failure rate and equivalent interruption duration time

- SAIFI $I^{\max }, S A I D I^{\max }, C I F^{\max }, C I D^{\max }$ : Maximum value of reliability indices such as SAIFI, SAIDI, CIF, and CID, respectively

- PD, QD: Active and reactive loads

\section{References}

1. Gao, Y., Hu, X., Yang, W., et al. "Multi-objective bilevel coordinated planning of distributed generation and distribution network frame based on multiscenario technique considering timing characteristics", IEEE Transactions on Sustainable Energy, 8(4), pp. 1415-1429 (2017).
2. Heidari, S., Fotuhi-Firuzabad, M., and Lehtonen, M. "Planning to equip the power distribution networks with automation system", IEEE Transactions on Power Systems, 32(5), pp. 3451-3460 (2017).

3. Moradi, S., Ghaffarpour, R., Ranjbar, A., et al. "Optimal integrated sizing and planning of hubs with midsize/large CHP units considering reliability of supply", Energy Conversion and Management, 148, pp. 974-992 (2017).

4. Mazhari, S.M., Monsef, H., and Romero, R. "A multiobjective distribution system expansion planning incorporating customer choices on reliability", IEEE Transactions on Power Systems, 31(2), pp. 1330-1340 (2016).

5. Koutsoukis, N.C., Georgilakis P.S., and Hatziargyriou, N.D. "Multistage coordinated planning of active distribution networks", IEEE Transactions on Power Systems, 33(1), pp. 32-44 (2018).

6. Ahmadigorji, M. and Amjady, N. "A new evolutionary solution method for dynamic expansion planning of DG-integrated primary distribution networks", Energy Conversion and Management, 82, pp. 61-70 (2014).

7. Naderi, E. and Seifi, H. "A dynamic approach for distribution system planning considering distributed generation", IEEE Trans Power Delivery, 27(3), pp. 1313-1322 (2012).

8. Zou, K., Prakash, A., and Muttaqi, K.M. "Distribution system planning with incorporating DG reactive capability and system uncertainties", IEEE Trans. Sustainable Energy, 3(1), pp. 112-123 (2012).

9. Bagheri, A., Monsef, H., and Lesani, H. "Integrated distribution network expansion planning incorporating distributed generation considering uncertainties, reliability, and operational conditions", Int. J. Electrical Power and Energy Systems, 73, pp. 56-70 (2015).

10. Saboori, H., Hemmati, R., and Abbasi, V. "Multistage distribution network expansion planning considering the emerging energy storage systems", Energy Conversion and Management, 105, pp. 938-945 (2015).

11. Heidari, S., Fotuhi-Firuzabad, M., and Kazemi, S. "Power distribution network expansion planning considering distribution automation", IEEE Trans. Power Syst., 30(3), pp. 1261-1269 (2015).

12. Munoz-Delgado, G., Contreras J., and Arroyo, J.M. "Joint expansion planning of distributed generation and distribution networks", IEEE Trans. Power Syst., 30(5), pp. 2579-2590 (2015).

13. AlKaabi, S.S., Zeineldin H.H., and Khadkikar, V. "Planning active distribution networks considering multi-DG configurations", IEEE Trans. Power Syst., 29(9), pp. 785-793 (2014). 
14. Gonecalves, R.R., Franco, J.F., and Rider, M.J. "Short-term expansion planning of radial electrical distribution systems using mixed-integer liner programming", IET Gener. Transm. Distrib., 9(3), pp. $256-266$ (2015).

15. Karimi, M. and Haghifam, M.R. "Risk based multi-objective dynamic expansion planning of subtransmission network in order to have eco-reliability, environmental friendly network with higher power quality", IET Generation, Transmission \& Distribution, 11(1), pp. 261-271 (2017).

16. Shen, X., Shahidehpour, M., Han, Y., et al. "Expansion planning of active distribution networks with centralized and distributed energy storage systems", IEEE Transactions on Sustainable Energy, 8(1), pp. 126-134 (2017).

17. Xing, H., Cheng, H., Zhang, Y., et al. "Active distribution network expansion planning integrating dispersed energy storage systems", IET Generation, Transmission \& Distribution, 10(3), pp. 638-644 (2016).

18. Muñoz-Delgado, G., Contreras, J., and Arroyo, J.M. "Multistage multistage generation and network expansion planning in distribution systems considering uncertainty and reliability", IEEE Transactions on Power Systems, 31(5), pp. 3715-3728 (2016).

19. Shivaie, M., Ameli, M.T., Sepasian, M.S., et al. "A multistage framework for reliability-based distribution expansion planning considering distributed generations by a self-adaptive global-based harmony search algorithm", Reliability Engineering \& System Safety, 139, pp. 68-81 (2015).

20. EPE, Relatório EPE-DEE-RE-081/2013, "Estudo de suprimento à região metropolitana de cuiabá-mato grosso", August (2013).

21. Kermanshahi, B. and Kamel, R.M. "Optimal size and location of distributed generations for minimizing power losses in a primary distribution network", Scientia Iranica, 16(2), pp. 137-144 (2009).

22. Memarzadeh, G. and Esmaeili, S. "Voltage and reactive power control in distribution network considering optimal network configuration and voltage security constraints", Scientia Iranica, 27(3), pp. 1481-1493 (2020). DOI: $10.24200 /$ sci.2018.20565

23. Billinton, R. and Grover, M.S. "Reliability evaluation in distribution and transmission systems", PROC. IEE, 122(5), pp. 517-524 (1975).

24. Garey, M.R. and Johnson, D.S., Computers and Intractability: A Guide to the Theory of NP Completeness, Freeman (1979).

25. Papadimitriou, C.H. and Steiglitz, K., Combinatorial Optimization: Algorithms and Complexity, Dover (1998).
26. Pirouzi, S., Aghaei, J., Vahidinasab, V., et al. "Robust linear architecture for active/reactive power scheduling of EV integrated smart distribution networks", Electric Power System Research, 155, pp. 8-20 (2018).

27. Pirouzi, S., Aghaei, J., Niknam, T., et al. "Proactive operation of electric vehicles in harmonic polluted smart distribution networks", IET Generation, Transmission and distribution, 12, pp. 967-975 (2018).

28. Pirouzi, S., Aghaei, J., Niknam, T., et al. "Two alternative robust optimization models for flexible power management of electric vehicles in distribution networks", Energy, 141, pp. 635-652 (2017).

29. Generalized Algebraic Modeling Systems (GAMS). [Online]. Available: http://www.gams.com.

\section{Biographies}

Mohammad Zohour-Attar received a BSc degree in Electrical Engineering from the Islamic Azad University, Dezful Branch, Iran in 2010; an MSc degree from the Science and Research University, Tehran, Iran in 2014; and a $\mathrm{PhD}$ degree from the Shiraz University of Technology (SUTECH), Shiraz, Iran in 2019. His research interests are power system operation and planning, renewable energy systems, smart grids, and the application of optimization methods in power systems.

Jamshid Aghaei received the BSc degree in Electrical Engineering from the Power and Water Institute of Technology, Tehran, Iran in 2003 and the MSc and PhD degrees in Power System Engineering from the Iran University of Science and Technology, Tehran in 2005 and 2009, respectively, all in Electrical Engineering. He is currently a Full Professor at the Shiraz University of Technology, Shiraz, Iran. His research interests include renewable energy systems, smart grids, electricity markets, power system operation, optimization, and planning. Dr. Aghaei is a member of the Iranian Association of Electrical and Electronic Engineers. He is a Subject Editor of the IET Generation Transmission Distribution, an Associate Editor of the IET Renewable Power Generation, and a Guest Editor of the IEEE Transactions on Industrial Informatics.

Taher Niknam received the BSc degree from Shiraz University, Shiraz, Iran in 1998 and the MSc and $\mathrm{PhD}$ degrees from the Sharif University of Technology, Tehran, Iran in 2000 and 2005, respectively, all in Power Electrical Engineering. $\mathrm{He}$ is a Full Professor at Shiraz University of Technology, Shiraz. His research interests include power system restructuring, impacts of distributed generations on power systems, optimization methods, and evolutionary algorithms. 
Ahmad Nikoobakht was born in Iran in 1988. He received the BSc degree in Electrical Engineering from Hormozgan University, Iran, in 2011, and the MSc and $\mathrm{PhD}$ degrees from Shiraz University of Technology, Shiraz, Iran, in 2013 and 2017, respectively. He is currently an Assistant Professor in the Electrical
Engineering Department of Higher Education Center of Eghlid, Eghlid, Iran. His research interests include renewable energy systems, smart grids, electricity markets, and power system operation and restructuring, as well as applied statistics and optimization in power system studies. 